\title{
NUMERICAL SIMULATION OF AN ENCLOSED LAMINAR JET DIFFUSION FLAME IN MICROGRAVITY ENVIRONMENT: COMPARISON WITH ELF DATA
}

\author{
Kezhong Jia, Rajasekhar Venuturumilli, Brandon J. Ryan and Lea-Der Chen \\ Department of Mechanical Engineering, NADS, The University of Iowa, Iowa City, IA 52242
}

\section{INTRODUCTION}

Enclosed diffusion flames are commonly found in practical combustion systems, such as the power-plant combustor, gas turbine combustor, and jet engine after-burner. In these systems, fuel is injected into a duct with a co-flowing or cross-flowing air stream. The diffusion flame is found at the surface where the fuel jet and oxygen meet, react, and consume each other. In combustors, this flame is anchored at the burner (i.e., fuel jet inlet) unless adverse conditions cause the flame to lift off or blow out. Investigations of bumer stability study the lift off, reattachment, and blow out of the flame.

Flame stability is strongly dependent on the fuel jet velocity. When the fuel jet velocity is sufficiently low, the diffusion flame anchors at the burner rim. When the fuel jet velocity is increased, the flame base gradually moves downstream. However, when the fuel jet velocity increases beyond a critical value, the flame base abruptly jumps downstream. When this "jump" occurs, the flame is said to have reached its lift-off condition and the critical fuel jet velocity is called the lift-off velocity. While lifted, the flame is not attached to the burner and it appears to float in mid-air. Flow conditions are such that the flame cannot be maintained at the burner rim despite the presence of both fuel and oxygen. When the fuel jet velocity is further increased, the flame will eventually extinguish at its blowout condition. In contrast, if the fuel jet velocity of a lifted flame is reduced, the flame base moves upstream and abruptly returns to anchor at the bumer rim. The fuel jet velocity at reattachment can be much lower than that at lift off, ilhustrating the hysteresis effect present in flame stability, e.g., see Gollahalli et al. [2].

Although there have been numerous studies of flame stability [1-14], the controlling mechanisms are not well understood. This uncertainty is described by Pitts [3] in his review of various competing theories of lift off and blow out in urbulent jet diffusion flames. There has been some research on the stability of laminar flames [1,4-5], but most studies have focused on turbulent flames [2-3,6-14]. It is also well known that the airflow around the fuel jet can significantly alter the lift off, reattachment and blow out of the jet diffusion flame. Buoyant convection is sufficiently strong in 1-g flames that it can dominate the flow-field, even at the burner rim. In normal-gravity testing, it is very difficult to delineate the effects of the forced airflow from those of the buoyancy-induced flow. Comparison of normal-gravity and microgravity flames provides clear indication of the influence of forced and buoyant flows on the flame stability.

The overall goal of the Enclosed Laminar Flames (ELF) investigation(STS-87/USMP-4 Space Shuttle mission, November to December 1997) is to improve our understanding of the effects of buoyant convection on the structure and stability of co-flow diffusion flame, e.g., see http://zeta.lerc.nasa.gov/expr/elf.htm. The ELF hardware meets the experiment hardware limit of the 35 -liter interior volume of the glovebox working area, and the $180 \times 220-\mathrm{mm}$ dimensions of the main 
door. The ELF experiment module is a miniature, fan-driven wind tunnel, equipped with a gas supply system. A $1.5-\mathrm{mm}$ diameter nozzle is located on the duct's flow axis. The cross section of the duct is nominally a $76-\mathrm{mm}$ square with rounded corners. The forced air velocity can be varied from about 0.2 to $0.9 \mathrm{~m} / \mathrm{s}$. The fuel flow can be set as high as $3 \mathrm{std}$. cubic centimeter $(\mathrm{cc})$ per second, which corresponds to a nozzle exit velocity of up to $1.70 \mathrm{~m} / \mathrm{s}$. The ELF hardware and experimental procedure are discussed in detail in Brooker et al. [20]. The 1-g test results are repeated in several experiments following the STS-87 Mission. The ELF study is also relevant to practical systems because the momentum-dominated behavior of turbulent flames can be achieved in laminar flames in microgravity. The specific objectives of this paper are to evaluate the use reduced model for simulation of flame lift-off and blowout.

\section{NUMERICAL}

The balance equations describing the transport of mass, momentum, energy, and individual species are solved using the computer program based on Sheu [16] and Sheu and Chen [17], as described in Jia [18]. The numerical scheme employs a controlvolume discretization method, staggered, non-uniform grids, and semi-implicit fractional step time marching method. The flux corrected transport method is applied to convective flux, along with a Quadratic Upstream Interpolation for Convective Kinematics (QUICK) to produce monotonic results. The projection method is used to solve the pressure equation. The numerical scheme is of second-order accuracy in spatial discretization and first-order in temporal difference. A second-order time difference scheme is also used to test the first-order scheme. Essentially the same results of steady-state solution are obtained. Since steady-state solution is intended for the present study, the first-order scheme is used. An explicit scheme is used for the convection and an implicit scheme for the diffusive transport. A four-step reduced mechanism based on a fifty-step starting mechanism is used for calculation of the chemical reaction rate [16-18]. Seventeen species are considered: seven $(\mathrm{CH} 4, \mathrm{H}, \mathrm{H} 2, \mathrm{H} 2 \mathrm{O}, \mathrm{CO}, \mathrm{CO} 2$ and $\mathrm{O} 2)$ are independent reactive species and the remaining ten species $(\mathrm{O}, \mathrm{OH}, \mathrm{C}, \mathrm{CH}, \mathrm{CH} 2, \mathrm{CH} 3, \mathrm{CHO}, \mathrm{CH} 2 \mathrm{O}, \mathrm{HO} 2$ and $\mathrm{H} 2 \mathrm{O} 2)$ are assumed to be steady-state species. Typical time step in the computation is set at $10 \mu \mathrm{s}$.

\section{RESULTS AND DISCUSSION}

The numerical simulation adopts a cylindrical enclosure of similar dimensions of the ELF hardware (70 $\mathrm{mm}$ in diameter and $166 \mathrm{~mm}$ in length): $35 \mathrm{~mm} \times 166 \mathrm{~mm}$. The simulation results discussed herein are focused at the prediction of ELF stability map. Numerical simulation successfully predicts stabilized, lifted and near blowout flames. For a fixed fuel jet velocity, the flame base moves to downstream locations when the co-flowing air velocity is increased. Further increase the co-flowing air velocity, the flame eventually reaches the blowout condition. Prior to the blowout, the flame length decreases, and a "tulip" like flame "tail" is predicted as well as a "disk" like flame shape just before the blowout condition is reached. It should be noted that the discussion of the flame shape is based on the simulation, as well as experimental, results obtained for the enclosed laminar flame studied.

Figure 1 shows the blowout map comparison between the numerical and the experimental results. Up to the fuel jet velocity of $1.0 \mathrm{~m} / \mathrm{s}$, the numerical prediction qualitatively agrees with the experiment results. However, the numerical calculation predicts a higher air velocity for the blowout to occur than that observed in the experiment. The numerical simulation predicts that, as shown in the experimental results, 
lower air velocities can cause the flame blowout when the fuel jet velocity is sufficiently high. However, because the tremendous computation time is needed to complete a simulation, the data for higher fuel velocity (greater than $1.0 \mathrm{~m} / \mathrm{s}$ ), and simulation for the $1 \mathrm{~g}$ conditions continues. An important experience we wish to share with the readers is that the simulation results defining the blowout are highly grid dependent. Specifically, mumerical error results in an erroneous "nearly stationary" flame and a "second branch" in the combustion efficiency curve. Without careful examination of numerical error, the "nearly stationary" flame might have been identified as the solution describing the "nearly stationary flame" that was observed in some of the experimental condition prior to the blowout. To address the numerical error, a Local Uniform Grid Refinement (LUGR) method based on an algorithm suggested by Trompert is implemented to the flame code. A test case using three grid configurations is shown in Fig. 2. As an example, the calculated oxygen concentration along the centerline of the flow is shown in Fig. 3 . The calculation is based on a reduced four-step mechanism. Encouraging results are obtained, and effort continues to study the flame stability in both $1-\mathrm{g}$ and $\mu-\mathrm{g}$ environments.

\section{Acknowledgments}

This work is supported by NASA Microgravity Science and Applications Division, Grant No. Grant No. NCC3-666, under the technical management of D.P. Stocker and M.K. King. The ELF investigation is carried out by Mission Specialists, Dr. Kalpana Chawla (NASA) and Dr. Takao Doi (NASDA) during the STS-87 mission. Members of ELF science teams are Dennis Stocker, John Brooker and L.D. Chen.

\section{References}

1. Chung, S.H. and Lee, B.J. Combust. Flame, 86:62-72 (1991).

2. Gollahalli, S.R., Savas, Ö. Huang, R.F., and Rodriquez Azara, J.L. Twenty-First Symposium (International) on Combustion, The Combustion Institute, Pittsburgh, 1986, pp. 1463-1471.

3. Pitts, W.M. Twenty-Second Symposium (International) on Combustion, The Combustion Institute, Pittsburgh, 1989, pp. 809-816.

4. Savas, Ö. and Gollahalli, S.R. J. Fluid Mech., 165:297-318 (1986).

5. Lee, B.J., Cha, M.S., and Chung, S.H. Combust. Sci. and Tech., 127:55-70 (1997).

6. Dahm, W.J.A. and Mayman, A.G., AIAA Journal, 28:7:1157-1162 (1990).

7. Feikema, D., Chen, R.-H. and Driscoll, J.F. Combust. Flame, 80:183-195 (1990).

8. Feikema, D., Chen, R.H. and Driscoll, J.F. Combust. Flame, 86:347-358 (1991).

9. Whol, K. Kapp, N.M., and Gazley, C. Third Symposium on Combustion and Flame and Explosion Phenomena, The Williams \& Wilkins Co., Baltimore, 1949, pp. 3-21.

10. Scholefiled, D.A. and Garside, J.E. Third Symposium on Combustion and Flame and Explosion Phenomena, The Wiliams \& Wilkins Co., Baltimore, 1949, pp. 102-110.

11. Kalghatgi, G.T. Combust. Sci. and Tech, 26:233-239 (1981).

12. Kalghatgi, G.T. Combust. Sci. and Tech., 41:17-29 (1984).

13. Takahashi, F., Mizomoto, M., Ikai, S., and Futaki, N. Twentieth Symposium (International) on Combustion, The Combustion Institute, Pittsburgh, 1984, pp. 295-302. 
14. Eickhoff, H., Lenze, B., and Leuckel, W. Twentieth Symposium (International) on Combustion, The Combustion Institute, Pittsburgh, 1984, pp. 311-318.

15. Burke, S.P. and Schumann, T.E.W. Ind. Eng. Chem., 20:998-1004 (1928).

16. Sheu, J.C., "Numerical Simulatio of Burke-Schumann Diffusion Flame Using Finite-Rate Chemical Kinetics," Ph. D. Dissertation, The University of Iowa, Iowa City, Iowa (1996).

17. Sheu, J.-C. and Chen, L.-D., AIAA J., Vol. 34, No. 10, pp. 2090-2098 (1996).

18. Jia, K, "The Structure and Stability of Enclosed Laminar Jet Diffusion Flame," Ph. D. Dissertation, The University of Iowa, Iowa City, Iowa (1999).

19. Sheu, J.-C. and Chen, L.-D., AIAA Paper 2000-690 (2000).

20. John E. Brooker, Dennis P. Stocker, K. Jia, L.-D., Chen, in Fifth Intemational Microgravity Combustion Workshop, NASA/CP-1999-208917, pp. 97-100 (1999)

\section{ACKNOWLEDGEMENTS}

This work is supported by NASA Microgravity Science and Applications Division, Grant No. Grant No. NCC3-666, under the technical management of D.P. Stocker and M.K. King. The ELF investigation is carried out by Mission Specialists, Dr. Kalpana Chawla (NASA) and Dr. Takao Doi (NASDA) during the STS-87 mission. Members of ELF science teams are Dennis Stocker, John Brooker and L.D. Chen.

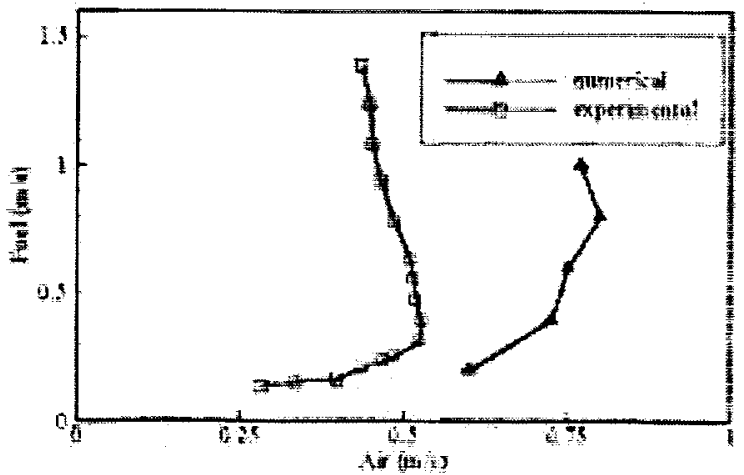

Figure 1. Comparison of blow-out conditions.

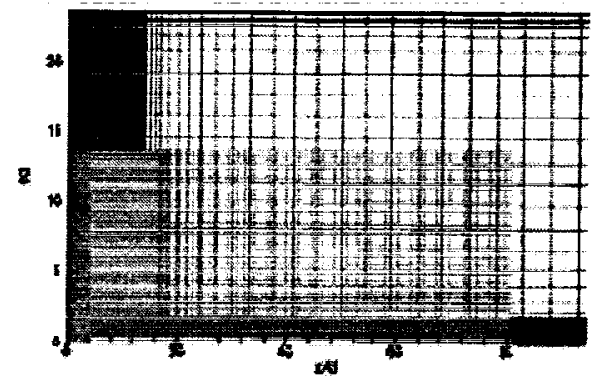

Figure 2. LUGR grid specification.

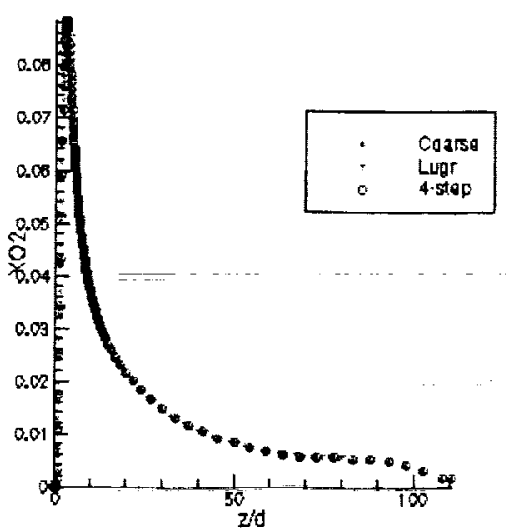

Figure 3. Comparison of calculated oxygen concentration along the centerline of the jet. 